\title{
An Energy Analysis of Impact Strength Tests Using Pendulum Hammers
}

\author{
Jan Godzimirski', Zenon Komorek², Andrzej Komorek ${ }^{3 *}$ \\ 1 Department of Mechatronics and Aviation, Military University of Technology, Warszawa, Poland \\ 2 Department of Advanced Materials and Technology, Military University of Technology, Warszawa, Poland \\ 3 Department of Aviation, Polish Air Force University, Deblin, Poland \\ * Corresponding author's e-mail: a.komorek@law.mil.pl
}

\begin{abstract}
An attempt to estimate the value of the deformation energy of a metal specimen and the research system during impact strength tests on pendulum hammers was made. In the experimental research it was found that the rectangular metal specimens of the same cross-sectional area exhibit different impact strength, depending on the direction of the load (bending stiffness) whereas the destruction work of such samples exposed to static bending is comparable. The article presents the results of the experimental research, completed with numerical calculations carried out to assess the value of the deformation energy during the impact tests. By performing numerical calculations, the authors estimated the deformation energies of specimens characterised by elastoplastic properties with reinforcement (bilinear) under destructive loads. The energy of the elastic deformation of the hammer arm was estimated analytically. On the basis of the research, it was found that in the impact strength test, a large part of the recorded energy is connected with the deformation of the test device, in particular, the pendulum which undergoes bending. Moreover, the recorded impact strength of the material is not proportional to its actual impact strength.
\end{abstract}

Keywords: impact strength test, pendulum hammer, deformation energy.

\section{INTRODUCTION}

The impact strength tests are conducted in order to investigate the influence of the load speed and deformation on the mechanical properties of construction materials $[1 \div 7]$ or joints $[8 \div 10]$. The construction materials which are impact loaded, usually demonstrate different mechanical characteristics compared to those which are calculated in static tests. The speeds of the deformation of $10 \leq \dot{\varepsilon} \geq 10^{3} \mathrm{~s}^{-1}$ are regarded as average deformation speeds which are characteristic, among others, of vehicles in collision [11]. The properties of materials at such deformation speeds are typically studied by means of different types of hammers: dropping or pendulum $[12,13]$. In the examinations of mechanical properties of metals, the commonly used testing method is the bend test conducted in accordance with the EN ISO 148-1:2010 standard. Due to the difficulties in the measurement of stresses and deformations, the result of the experiment comes down to an evaluation of the destruction energy of a standardized specimen. Impact strength $U$ is the ratio of work $L_{u}$ necessary to fracture the specimen to its crosssection $A_{0}$ at the place of the notch.

$$
U=\frac{L_{U}}{A_{0}}\left\lceil\frac{k J}{m^{2}}\right]
$$

The definition of impact strength, described by equation (1), is not specified by physics and does not allow a comparison of the results obtained in impact strength tests, in which specimens with different dimensions or other notch shapes have been used. The investigation of the impact strength of adhesive joints also indicates that the impact strength, described by equation (1), significantly depends on the used test machine. Thus, a significant part of the measured energy is the energy of elastic strain of the test machine of which the researchers carrying out 


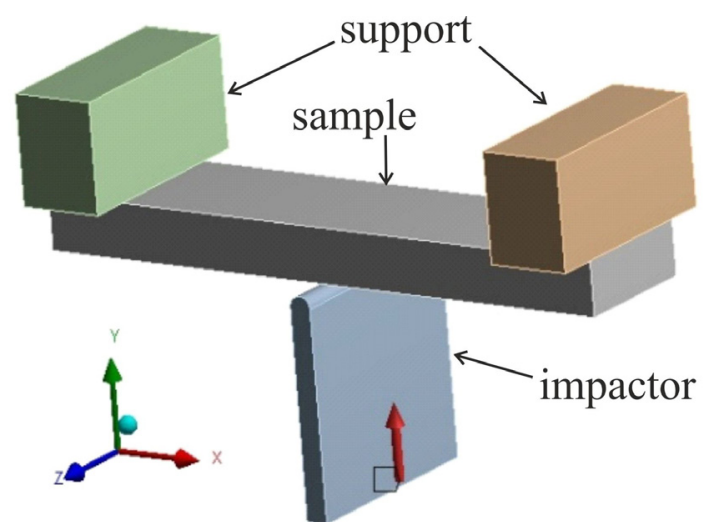

Fig. 1. Model of specimen loading in the analysed test

the impact tests are often unaware. The studies on the influence of the testing device and its foundation on the recorded results are rarely conducted $[14,15]$. The authors conducted experimental and numerical calculations in order to estimate which part of the measured energy of impact strength concerns the destruction of the sample. The purpose of the presented article is to show the existence of the problem with the interpretation of the impact tests results for the persons who will carry out such tests.

\section{INITIAL NUMERICAL ANALYSES}

The numerical calculations were performed in the Ansys 14 system, using the Static Structural module in order to estimate the deformation energy of rectangular specimens, made of an aluminum alloy, sized $12.5 \times 5 \times 55$, in which the load bending is equal to the one which occurs in an impact strength test. Explicit Dynamics module of Ansys 14 does not compute the deformation energy. The model of specimen loading in a dynamic bending test is shown in Figure 1. Friction was declared between the support and the specimen (coefficient of friction $f=0.1$ ). A cylindrical edge of a steel loaded element was connected with the bended specimen by bonded contact. The declared mesh sizing was $0.9 \mathrm{~mm}$.

The backs of supports were taken to all degrees of freedom. The bending specimen was prevented from moving in the direction of the $\mathrm{Z}$ axis, and the loading element in the $\mathrm{Z}$ and $\mathrm{X}$ directions.

The specimen material was declared as elastoplastic with reinforcement (bilinear). Assuming that the test material will be duralumin AW2117T3 and knowing its mechanical proper- ties $\left(R_{0.2}=240 \mathrm{MPa}, R_{m}=420 \mathrm{MPa}\right.$ and $A_{10}$ $=15 \%)[16]$, the authors adopted the Young's modulus $E=72 \mathrm{GPa}$, the yield strength $R_{0.2}=$ $240 \mathrm{MPa}$ and the reinforcement modulus $D=$ $1,200 \mathrm{MPa}$. In order to estimate the force values, at which the analyzed specimens should be destroyed while bending, they were loaded incrementally up to the values which cause the maximum principal stresses of approximately 400 $\mathrm{MPa}$, being close to ultimate strength and such strengths where the programme might be able to perform calculations. The models of the speci-

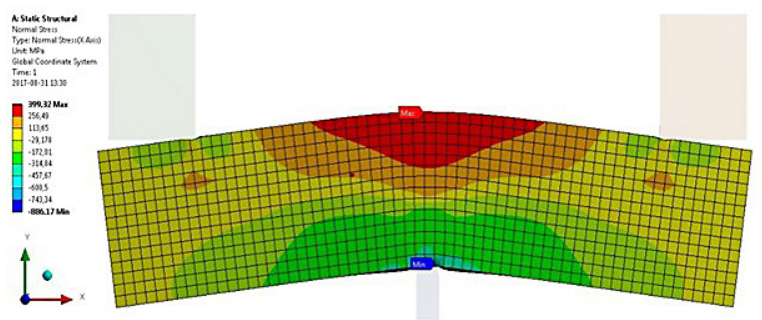

Fig. 2. Normal stresses in the bended specimen whose configuration equals $12.5 \times 5$ loaded with a force of $7.7 \mathrm{kN}$

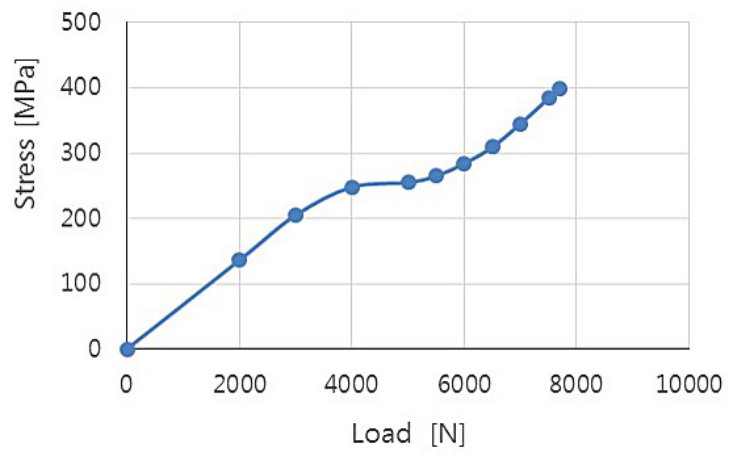

Fig. 3. Dependence of maximum normal positive stresses upon the load of the bended specimen of larger bending stiffness $(12.5 \times 5)$

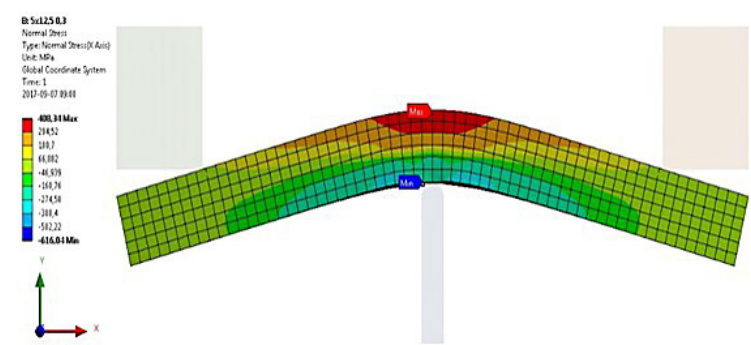

Fig. 4. Normal stresses in the bended specimen whose configuration equals $5.12 \times 5$ loaded with a force of $3.1 \mathrm{kN}$ 


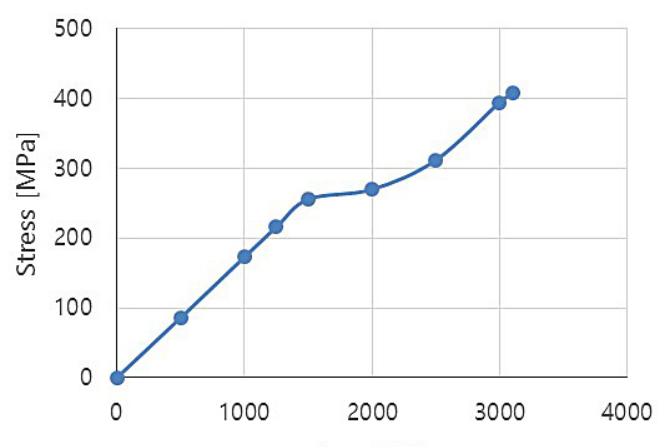

Fig. 5. The dependence of the maximum normal stresses upon the load of the bended specimen of lower bending stiffness $(5 \times 12.5)$

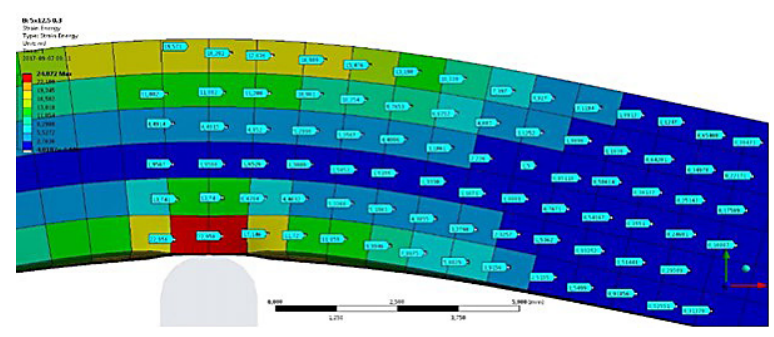

Fig. 6. The distribution of the deformation energy in the components of the specimen with a configuration of $12.5 \times 5$, loaded with a force of $7.7 \mathrm{kN}$

mens were loaded in two configurations: along the side of $12.5 \mathrm{~mm}$ and of $5 \mathrm{~mm}$ (Figures 2-5).

The calculation of energy deformation of the examined samples was conducted for the loads below $7,700 \mathrm{~N}$, for a sample of greater stiffness and for 3,100 $\mathrm{N}$ for a sample of lesser stiffness, i.e. for such loads at which the static strength is exceeded in the material. The deformation energy of consecutive elements (Fig. 6) was measured and added. This enabled to estimate the deformation energy of the specimen with increased bending stiffness at approximately $16 \mathrm{~J}$ and for a sample with lower stiffness - at approximately $9.5 \mathrm{~J}$.

Calculations showed that the impact strength of the tested samples should differ significantly depending on the direction of their loading with the impactor due to the different value of strain energy at maximum stresses equal to the strength of the material.

\section{EXPERIMENTAL RESEARCH}

Specimens for impact strength tests, $12.5 \mathrm{~mm}$ wide and $55 \mathrm{~mm}$ long, were cut out with a waterjet method from the available $5 \mathrm{~mm}$ thick aluminum alloy sheet, along with 3 dog-bone specimens with dimensions consistent with the EN ISO 69892-1: 2010 standard. The tensile test was conducted for the identification of the examined material. Experimental tests were conducted on the Instron 8501 testing machine with a load range up to $100 \mathrm{kN}$ using the Instron 2620-601 dynamic extensometer with a measuring range of $5 \mathrm{~mm}$. The tests were carried out in accordance with EN ISO 6892-1: 2010 with method B. The traverse speed was 2 $\mathrm{mm} / \mathrm{min}$, which corresponds to the deformation rate $0.007 \mathrm{1} / \mathrm{s}$ for the measuring section $l_{O}=50$ $\mathrm{mm}$. In the static tensile test, the authors obtained the results as below (Table 1).

The conducted experiment shows that the examined material is the AW $2024 \mathrm{~T} 3$ aluminum alloy, and thus, it has greater strength than the one assumed in numerical calculations.

The impact strength tests of specimens, sized $12.5 \times 5 \times 55 \mathrm{~mm}$, were carried out using the Charpy method in accordance with the EN ISO 1481:2010 standard. The Wolpert-Wilson PW 30 pendulum hammer was used in the tests. The energy of the hammer's pendulum was equal to $300 \mathrm{~J}$ at a velocity of $5 \mathrm{~m} / \mathrm{s}$. It was possible to specify the destruction energy of six samples, three of which were examined in the configuration settings with the long side towards the pendulum impact, and three with a shorter side setting. The destruction energy of the samples examined in such manner differed considerably (Table 2) but the ratio of recorded energies did not correlate with the results of numerical calculations of strain energy.

In addition, the static three-bending tests of specimens with a configuration of $5 \times 12.5 \mathrm{~mm}$ and $12.5 \times 5 \mathrm{~mm}$ (beam supported on both sides and

Table 1. Results of static tensile tests

\begin{tabular}{|c|c|c|c|c|}
\hline Sample No. & $\mathbf{1}$ & $\mathbf{2}$ & $\mathbf{3}$ & Mean value \\
\hline$\sigma_{02}[\mathrm{MPa}]$ & 327 & 330 & 325 & 327.3 \\
\hline $\mathrm{R}_{\mathrm{m}}[\mathrm{MPa}]$ & 453 & 453 & 443 & 449.7 \\
\hline $\mathrm{A}[\%]$ & 20 & 23 & 18 & 20.3 \\
\hline $\mathrm{E}[\mathrm{GPa}]$ & 70.7 & 75.7 & 72.9 & 73.1 \\
\hline
\end{tabular}

Table 2. Recorded destruction energies of samples

\begin{tabular}{|c|c|c|}
\hline Configuration & $12.5 \times 5$ & $5 \times 12.5$ \\
\hline & 128.6 & 52.8 \\
Recorded energy [J] & 192 & 40 \\
& 220 & 43 \\
\hline Mean energy [J] & 180.2 & 45.27 \\
\hline
\end{tabular}




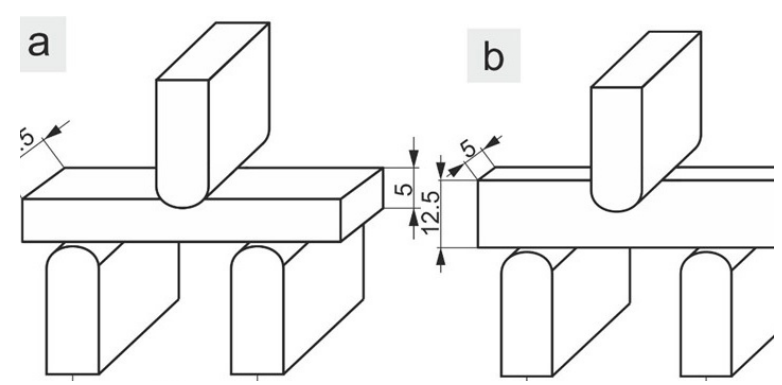

Fig. 7. Diagrams of static bending tests: a) test of $5 \times 12.5$ sample; b) test of a $12.5 \times 5$ sample

centrally loaded with force), were carried out with the support distance of $40 \mathrm{~mm}$ (Fig. 7), which is the same as in the case of the impact strength tests.

The dependence between strain and loading was achieved (Fig. 8 and 9). Integrating the surface area under the obtained curves allowed assessing the work of the loading force while bending specimens for approximately $40 \mathrm{~J}$, regardless of the loading direction, which means that these works do not correlate with the impact destruction energies and are smaller than the energies recorded in the impact tests.

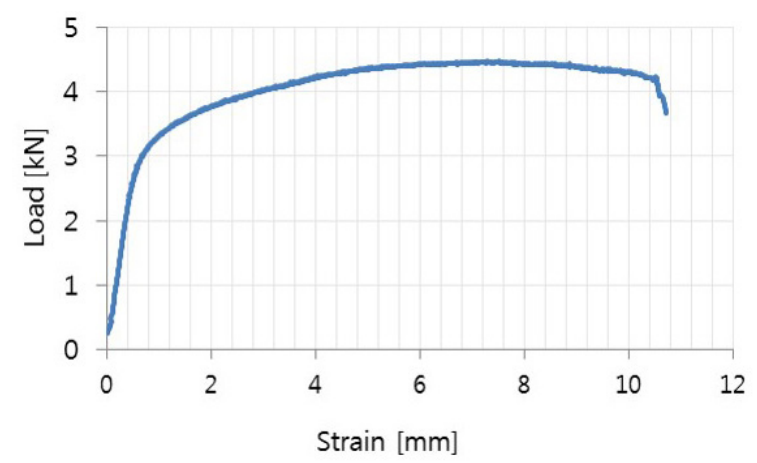

Fig. 8. Load-strain curve obtained in a bending test of a specimen whose configuration equals $5 \times 12.5 \mathrm{~mm}$

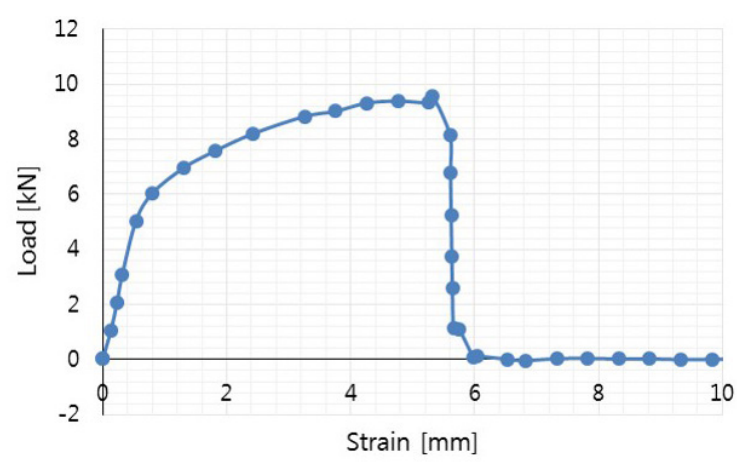

Fig. 9. Load-strain curve obtained in a bending test of a specimen whose configuration equals $12.5 \times 5 \mathrm{~mm}$

\section{NUMERICAL ANALYSIS}

Numerical calculations, similar to the preliminary ones, are taking into consideration the properties of the AW 2024T3 material. Knowing the experimentally designated deformation of material $\mathrm{A}=20 \%$, it was possible to calculate the true strain:

$$
\varepsilon_{r Z}=\frac{\varepsilon}{1+\varepsilon}=\frac{0,2}{1+0,2}=0.167
$$

Knowing the value of true strains, the authors computed the ultimate strength of alloy AW 2024T3:

$R_{m r z}=R_{m}\left(1+\varepsilon_{r z}\right)=453(1+0.167)=528.6 \mathrm{MPa}(3)$

In order to calculate the reinforcement modulus from the actual ultimate strength, the authors deduced the yield strength; the obtained difference was divided by true strain:

$$
D=\frac{R_{m r z}-R_{0.2}}{\varepsilon_{r Z}}=\frac{528.6-327.3}{0.167}=1205 \mathrm{MPa}
$$

Having declared the calculated material constants, computations were performed to determine the force values in which, in impact tested specimens, stress values close to true failure stress of material will be reached and next the material deformation energy was calculated under such loads (Table 3).

The calculated energies were larger than the ones for the AW 2017T3 material and considerably smaller from the registered ones in impact strength experimental research.

The value of the critical strain energy release rate (toughness) of aluminum alloys is within 8-30 $\mathrm{kJ} / \mathrm{m}^{2}$, depending on their resistance [17]. Highstrength alloys, as in the case of the WA 2024T3 alloy, are characterised by decreased toughness. Taking into account the size of the cross-sectional area of the examined samples $A_{0}=6.25 \cdot 10^{-5} \mathrm{~m}^{2}$, the energy required to propagate the crack along the whole cross section, does not exceed $2 \mathrm{~J}$. Therefore, it appears that a large portion of the energy measured in impact strength tests is transformed into elastic energy and heat of the research system; also in the deformations occurring at impact strength test speeds, a slight increase in the material yield strength is likely to take place.

Table 3. Force, maximum stresses and deformation energy of the bended specimens

\begin{tabular}{|c|c|c|c|}
\hline Sample & Force [N] & $\boldsymbol{\sigma}_{\max }[\mathrm{MPa}]$ & Energy [J] \\
\hline $12.5 \times 5$ & 9,700 & 490 & 20.79 \\
\hline $5 \times 12.5$ & 4,000 & 517 & 14.04 \\
\hline
\end{tabular}




\section{Elastic energy of the bended pendulum arm}

It was assumed that bending the pendulum arm with force which causes the destruction of the specimen can absorb a significant part of the energy recorded during the impact tests.

The performed dynamic calculations demonstrate that the stresses in the pendulum arm change over time and prove that the wave phenomena occur. The pendulum model and stress maps are shown in Figures 10-13.

The dynamic numerical calculations were performed in the Ansys 16.2 system, using the Explicit Dynamics module in order to estimate the load of the pendulum arm during the dynamic bending of a cuboid aluminum alloy specimen.

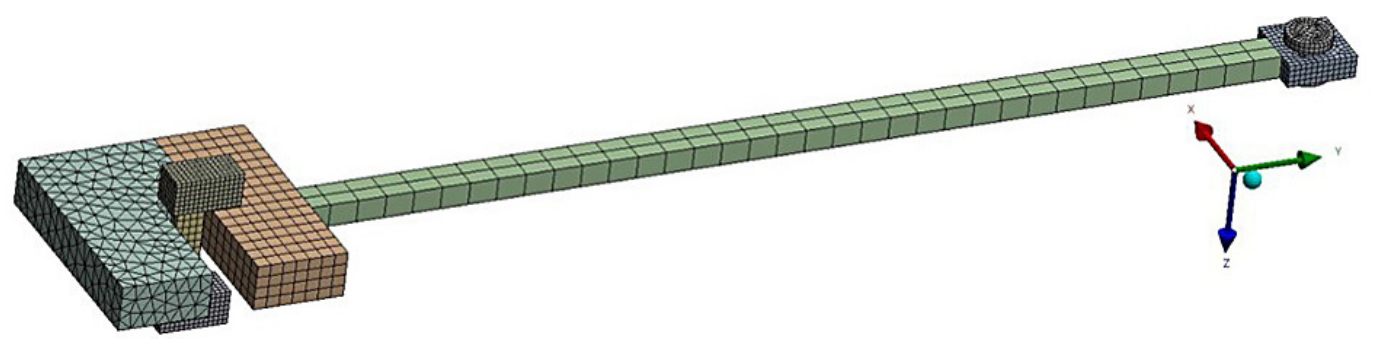

Fig. 10. Numerical model of the pendulum

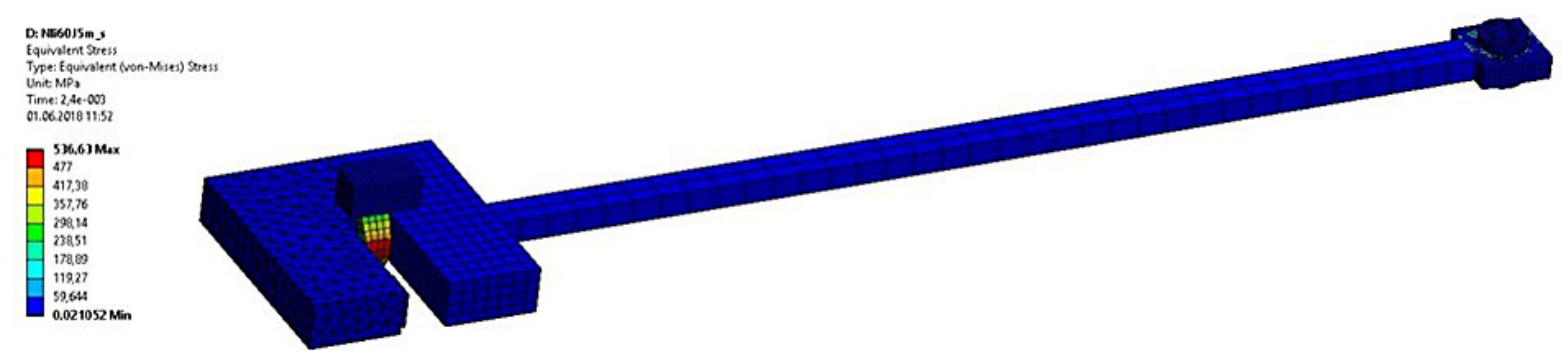

Fig. 11. Stresses for $60 \mathrm{~J}$ energy and $5 \mathrm{~m} / \mathrm{s}$ velocity (close to the duralumin specimen strength)

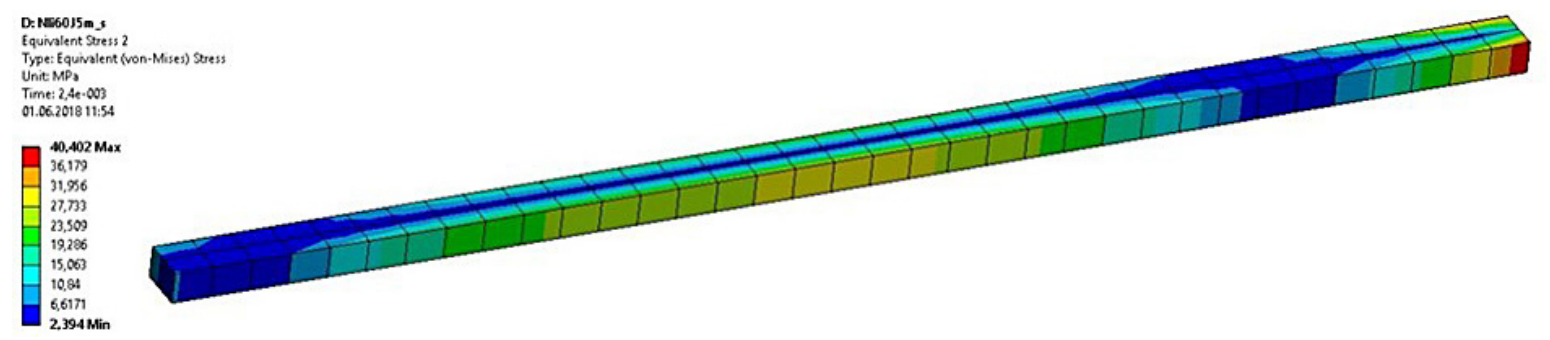

Fig. 12. Distribution of stresses in the pendulum arm for $60 \mathrm{~J}$ energy and $5 \mathrm{~m} / \mathrm{s}$ velocity in $2.4 \cdot 10^{-3} \mathrm{~s}$

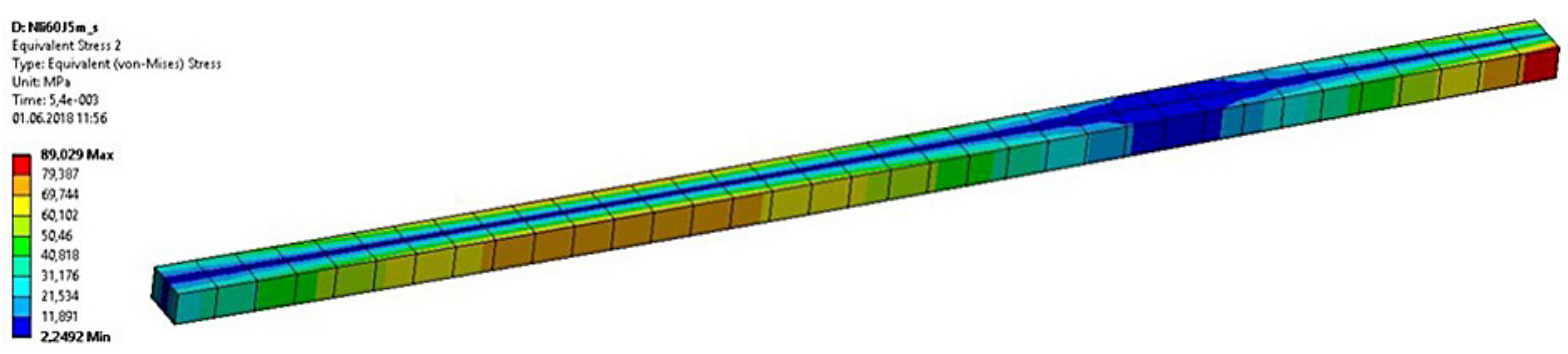

Fig. 13. Distribution of stresses in the pendulum arm for $60 \mathrm{~J}$ energy and $5 \mathrm{~m} / \mathrm{s}$ velocity in $5.4 \cdot 10^{-3} \mathrm{~s}$ 
The stress distributions were analyzed because the strain energy calculation is not possible in this module. The possibility of frictionless rotation of the pendulum on the pin was assumed (Fig. 10). The elements of the pendulum were given linearelastic properties of steel, and the density of the beater material was declared so that at the pendulum's velocity $5 \mathrm{~m} / \mathrm{s}$, its energy equalled $60 \mathrm{~J}$.

For the load time of $2.4 \cdot 10^{-3} \mathrm{~s}$ the stresses in the specimen were close to the strength of the sample material (Fig. 11). The distribution of Von Mises stresses in the pendulum arm for the same load time is depicted in Fig. 12. The change in the value and distribution of stresses in the pendulum arm for the time $5.4 \cdot 10^{-3} \mathrm{~s}$ (Fig. 13) shows the occurrence of wave phenomena during the dynamic investigations carried out with declared speeds.

It is possible to find an analytical dependence which specifies the energy of elastic deformation of the pendulum in the function of its dimensions, shape and load if the pendulum is regarded as a beam fixed on one side and loaded with focused force (such an assumption is a large simplification since a relevant analysis would require an inclusion of the pendulum inertia forces). The maximum stresses in a beam with a rectangular cross section, impact loaded to bending, are described by the following equation:

$$
\sigma_{\text {max }}=\frac{M_{g(x)}}{W}=\frac{6 F \times x}{b \times h^{2}}
$$

where: $M_{g}$ - bending moment, $W$ - bending strength indicator, $F$ - force, $x$ - distance of the considered cross-section to the force, $b$ - width of the pendulum arm cross-section, $h$ - height of the pendulum cross-section arm.

The unit energy of elastic deformation of the material is a function of stresses and Young's modulus:

$$
U_{j}=\frac{\sigma^{2}}{2 E}
$$

where: $E$ - Young's modulus.

The stresses in the bent beam section change linearly and their value is, inter alia, a function of the distance $y$ from the centroidal axis:

$$
\sigma_{(y)}=\frac{2 \sigma_{\max }}{h} \times y
$$

thus:

$$
\sigma_{(y)}^{2}=\frac{4 \sigma_{\max }^{2}}{h^{2}} \times y^{2}
$$

In order to calculate the mean value of the square of the stresses in any cross-section, it is necessary to integrate the function described by relationship (8) after $y$ in the range from 0 to $h / 2$, and then divide it by the interval of integration:

$$
\begin{gathered}
\int_{0}^{h / 2} \frac{4 \sigma_{\max }^{2} \times y^{2}}{h^{2}} d y=\frac{\sigma_{\max }^{2}}{6} h \\
\sigma_{\grave{s} r}^{2}=\frac{\sigma_{\max }^{2}}{3}
\end{gathered}
$$

Taking into account the dependencies $(6,7$, and 10), we obtain:

$$
U_{j}(x)=\frac{\sigma_{\max }^{2}(x)}{6 E}=\frac{6 F^{2} \times x^{2}}{E \times b^{2} \times h^{4}}
$$

In order to calculate the total deformation energy, it is necessary to integrate the unit energy with regard to the rod volume, assuming that $d V=(b \times h) d x$ :

$$
\int_{0}^{l} \frac{6 F^{2} \times x^{2}}{E \times b \times h^{3}} d x=\frac{2 F^{2} \times l^{3}}{E \times b \times h^{3}}
$$

where: $l-$ length of the pendulum.

Dependence (12) shows that the pendulum elastic energy relies on the square of the force destroying the examined specimen and on the pendulum geometry.

By a similar methodology, the authors determined a dependence enabling an assessment of the pendulum deformation energy with a circular cross-section:

$$
U=\frac{2 F^{2} \times l^{3}}{3 \pi E \times r^{4}}
$$

where: $r$ radius of the rod

and for the tube:

$$
U=\frac{2 F^{2} \times l^{3}}{3 \pi E \times\left(r^{4}-r_{0}^{4}\right)}
$$

where: $r$ is the outer surface of the tube, and $r_{0}$ is the radius of the hole.

The deformation energy of the tube-shaped pendulum, with a diameter of $56 \mathrm{~mm}$, wall thickness of $3 \mathrm{~mm}$ and a length of $650 \mathrm{~mm}$ calculated for load $F=9,700 \mathrm{~N}$, is equal to $121 \mathrm{~J}$ and for the force of $4,000 \mathrm{~N}-20.6 \mathrm{~J}$; these energies have higher values than the deformation energy of the examined specimens. The sums of the deformation ener-

Table 4. Energy analysis of the impact test

\begin{tabular}{|c|c|c|c|c|c|c|}
\hline Sample & $\begin{array}{c}\text { Recorded energy } \\
{[\mathrm{J}]}\end{array}$ & $\begin{array}{c}\text { Sample energy } \\
{[\mathrm{J}]}\end{array}$ & $\begin{array}{c}\text { Pendulum energy } \\
{[\mathrm{J}]}\end{array}$ & $\begin{array}{c}\text { Energy of dam- } \\
\text { age }[\mathrm{J}]\end{array}$ & $\begin{array}{c}\text { Total energy } \\
{[\mathrm{J}]}\end{array}$ & $\mathrm{E}_{\text {rec }} / \mathrm{E}_{\text {tot }}$ \\
\hline $12.5 \times 5$ & 180.2 & 20.8 & 121.0 & 2.0 & 143.8 & 1.25 \\
\hline $5 \times 12.5$ & 45.3 & 14.0 & 20.6 & 2.0 & 36.6 & 1.24 \\
\hline
\end{tabular}


gies of the test specimens (for load causing tension close to the ultimate strength of the examined material), the deformation energy of the tube-shaped pendulum and the fracture energy were compared with the recorded energy, as listed in Table 4.

The sums of the computed destruction energies of the specimens and the deformations of the pendulum proved to be smaller than the energy recorded during the examination. On the basis of the numerical calculations, it is evident that the energies of elastic deformations of the reinforcement and the impactor are so insignificant that they may be disregarded. Thus, the cause of the differences between the recorded and calculated energy might be an increase in the strength of the examined material under dynamic load as well as heat generation due to friction.

\section{THE SPEED OF DEFORMATION OF THE TEST SPECIMENS}

In order to assess the speed of the material deformation in the course of the examination of impact strength, the authors conducted the calculations which take into account the conditions of the experiment. The investigated specimen was treated as a beam, supported on both sides, and loaded with a centrally focused force. The deflection of such a beam $f$ is described as follows:

$$
f=\frac{F \times l^{3}}{48 \times E \times J}
$$

After the transformation taking into account the moment of inertia of the rectangular cross section, there is:

$$
F=4 \frac{E \times b \times h^{2} \times f}{l^{3}}
$$

For the impact load model in question:

$$
M_{g}=\frac{F \times l}{4}=\frac{E \times b \times h^{3} \times f}{l^{2}}
$$

maximum stresses are the quotient of the bending moment and the flexural strength factor:

$$
\sigma=6 \frac{E \times h \times f}{l^{2}}
$$

and the maximum deformation is described by the dependency:

$$
\varepsilon=6 \frac{h \times f}{l^{2}}
$$

In order to calculate the speeds of the deformation, it is necessary to divide them by the time after which there will be a deflection of the sample valued $f$ :

$$
\dot{\varepsilon}=\frac{\varepsilon}{t}=6 \frac{h \times V}{l^{2}}
$$

where $V$ is the speed of the pendulum.

In experimental studies, the impact speed of the pendulum equalled $5 \mathrm{~m} / \mathrm{s}$, which allows estimating that the speed of the deformation of a stiffer sample was approximately $234 \mathrm{~s}^{-1}$, and in the case of smaller stiffness, it was equal to $94 \mathrm{~s}^{-1}$. These are the speeds of deformation categorised as the medium-sized [11], for which the impact of inertia forces on the mechanical properties of metals is relevant. In relation to [18], in such a range of the deformation rate (up to $103 \mathrm{~s}^{-1}$ ), there is an increase in the value of the plastic flow stress, approximately linearly with the logarithm of the rate of deformation. On the basis of the results of the research conducted for copper [19] it can be assumed that an increase in yield strength at medium speeds of deformation can reach approximately $25 \%$. An increase in material strength resulting from the speed of deformation in impact tests should result in an increase in the force causing the material to exceed its strength, and thus increased deformation energy of the tested material and the research system.

\section{CONCLUSIONS}

On the basis of the conducted analyses, it may be concluded that in the impact strength test, a larger portion of the recorded energy is related to the deformation energy of the test device, in particular to the pendulum which is bending. Therefore, the results of the impact tests conducted on different research devices should vary considerably.

Length and bending stiffness exert the largest impact on the value of the strain energy of the pendulum arm. The publication [20] shows that a $20 \%$ increase in the pendulum stiffness results in a $9 \%$ increase in the registered energy of the impact-damaged samples. Therefore, it seems reasonable to claim that the standard beyond the dimensions of the specimens should impose these two characteristics of the test device: length and bending stiffness of the pendulum arm.

The velocity of impactor is an important parameter of the impact tests, since it determines the material deformation speed. The plastic flow stresses of the material increase, and thus the recorded energy increase along with the deformation speed. 
In order to fracture the sample material which is characterised with higher impact strength, it is necessary to apply greater force. The strain energy of the pendulum depends on the square of the force. Therefore, the recorded impact strength of the materials is not proportional to their actual impact strength (recorded impact strength of materials more resistant to impact loading is inflated, compared to those which are less resistant). In the case of the tested samples with different bending stiffness, the ratio of destructive forces was 2.425; therefore, the pendulum deformation energy destroying a sample with higher stiffness should be about 5.9 times higher than the deformation energy destroying a sample with lower stiffness.

The test standard should contain not only the conditions regarding the samples, the method of testing and the analysis of test results, but also the requirements for the testing device, with particular emphasis on machine rigidity and bending of the pendulum arm.

In further studies, the authors are going to compare the results of impact tests of identical specimens loaded at the same speed and energy on the research devices that differ in the rigidity of bending pendulum arms.

Despite the fact that the results of standard tests depend on many factors, such as the shape and dimensions of the samples and the type of test device and test conditions, they have practical significance, as they allow to compare the resistance of different materials to dynamic loads qualitatively, if the samples of standard shape are tested on the same testing device.

\section{REFERENCES}

1. Harada M., Ohya T., Iida K., Hayashi H., Hirano K., Fukuda H. Increase impact strength of biodegradable poly(lactic acid)/poly(butylene succinate) blend composites by using isocyanate as a reactive processing agent. J Appl Polym Sci, 106(3), 2007; 1813-1820. DOI: 10.1002/app.26717.

2. Ye Y., Chen H., Wu J., Ye L. High impact strength epoxy nanocomposites with natural nanotubes. Polymer, 48(21), 2007; 6426-6433.

3. Yasa E., Deckers J., Kruth J.P., Rombouts M., Luyten J. Experimental Investigation of Charpy Impact Tests on Metallic SLM parts. Innovative Developments in Design and Manufacturing: Advanced Research in Virtual and Rapid Prototyping - Proceedings of VRP4, Leiria, 2006.
4. Rzepa S., Bucki T., Konopík P., Džugan J., Rund M., Procházka R. Influence of specimen dimensions on ductile-to-brittle transition temperature in Charpy impact test. IOP Conference Series: Materials Science and Engineering, 179(1), 2017. DOI: 10.1088/1757-899X/179/1/012063.

5. Camposo Pereira A. et all, Charpy impact tenacity of epoxy matrix composites reinforced with aligned jute fibers, Journal of Materials Research and Technology, 7(4), 2018, 520-527.

6. Száraz Z., Hähner P., Stráská J., Ripplinger S., Effect of phase separation on tensile and Charpy impact properties of MA956 ODS steel, Materials Science and Engineering: A, 700, 2017, 425-437, https://doi.org/10.1016/j.msea.2017.06.010.

7. Ningning Liang, Yonghao Zhao, Jingtao Wang, Yuntian Zhu, Effect of grain structure on Charpy impact behavior of copper, Scientific Reports, 7, 2017 44783, DOI https://doi.org/10.1038/srep44783.

8. Adams R.D., Harris J.A. A critical assessment of the block impact test for measuring the impact strength of adhesive bonds. Int J Adhes Adhes, 16, 1996; 61-71.

9. Asgharifar M., Kong F., Carlson B., Kovacevic R. Dynamic analysis of adhesively bonded joint under solid projectile impact. Int J Adhes Adhes, 50, 2014; 17-31.

10. Yeong-Seok L., Sang-Hyuk K., Kwang-Jin L., Effect of Residual Stress on the Mechanical Properties of FSW Joints with SUS409L, Advances in Materials Science and Engineering, 2018, Article ID 9890234, 8 pages https://doi. org/10.1155/2018/9890234.

11. Meyers M.A. Dynamic behaviour of materials; Wiley and Sons: New York, USA, 1994.

12. Tanks J., Sharp S., Harris D., Charpy impact testing to assess the quality and durability of unidirectional CFRP rods, Polymer Testing Volume 51, 2016, 63-68.

13. Siewert T.A., Vigliotti D.P., Dirling L.B., and McCowan C.N., Performance Verification of Impact Machines for Testing Plastics, J Res Natl Inst Stand Technol, 104(6), 1999; 557-565., doi: 10.6028/jres.104.034.

14. Lucon E., McCowan C.N., Santoyo R.A. Instrumented Impact Testing: Influence of Machine Variables and Specimen Position - Open Report of the Belgian Nuclear Research Centre, Boeretang, 2008.

15. Lucon E., Santoyo R.A. A Comparative Analysis of NIST Charpy Machines and Internal Reference Materials - Report of National Institute of Standards and Technology U.S. Department of Commerce, Boulder, USA, 2016. DOI: http://dx.doi. org/10.6028/NIST.IR.8145.

16. Kutz M. (Ed.) Mechanical Engineers' Handbook; Wiley and Sons: Hoboken, USA, 2015. 
17. Ashby M.F., Jones D.R.H. Engineering Materials 1. An Introduction to Properties, Applications and Design; Elsevier: Oxford, Great Britain, 2005.

18. Moćko W., Janiszewski J., Radziejewska J., Grązka M. Analysis of deformation history and damage initiation for 6082-T6 aluminium alloy loaded at classic and symmetric Taylor impact test conditions, International Journal of Impact Engineering, $75,2015,203-213$
19. Follasbee P.S., Kocks U.F. A Constitutive Description of Deformation of Copper Based on the Use of Mechanical Threshold Stress as an Internal State Variable, Acta Metall., 36,1988: 81-93.

20. Manahan M.P., Stonesifer R.B., Siewert T.A., McCowan C. N., and Vigliotti D.P., Observations on differences between the energy determined using an instrumented striker and dial/encoder energy, European Structural Integrity Society, 30, 2002, 229-236. 